\title{
Contextual Insights into Home Energy Relationships
}

\author{
Germaine Irwin*, Nilanjan Banerjee***, Amy Hurst*, Sami Rollins** \\ Computer Science and Electrical Engineering***, Information Systems*, Computer Science** \\ University of Maryland, Baltimore County, University of San Francisco
}

\begin{abstract}
Home energy management systems have become more widely available due to the continued emphasis on environmental consciousness, the increased implementations of smart grids/smart meters, and the desire to have more control over one's home. A key challenge in designing effective home energy management systems is understanding the underlying causes that impact home energy consumption. To address this challenge, in this paper, we present results from an interview-based study of 22 households in Baltimore City, Maryland, across a wide range of income groups, occupant types (age, number of home occupants, and occupation), and house types (rentals and userowned). Using a semi-structured interviewing process, we present several insights regarding home energy consumption that impact the usage and effectiveness of current and future systems. As an example, we find that non-human occupants, such as pets, significantly influence home energy consumption. Additionally, household dynamics and hierarchy, as well as routine behavior and individual habits, produce significant decision making challenges for an energy management system. Finally, problems with home insulation and appliance age are seen as fiscally insurmountable, suggesting that newer, cheaper, and readily available retrofit solutions would be beneficial.
\end{abstract}

\section{INTRODUCTION}

A growing emphasis on sustainability and environmental awareness, as well as continued interest in reducing the cost of home energy bills, has made residential energy management a critical application of ubiquitous and pervasive computing technology. While underlying advancements in sensing and feedback technologies enable a new class of home energy management systems, designing such systems requires a thorough understanding of the fundamental contextual factors that impact the relationship between residents and their perception and usage of home energy. Understanding, for example, who in the home is responsible for making energy-saving decisions can help to guide the design of a feedback system. Moreover, understanding which routines or habits are thought to be necessary or required can inform recommendations made by an energy management system [24].

The state-of-the-art approach to mining ties between context and energy usage relies on deploying a rich set of sensors to collect data on factors such as ambient temperature, humidity, and occupancy. The sensor data is then used for post-priori analysis to infer ties between contextual cues and home or appliance energy consumption. The success of such an approach relies on intelligently choosing the right set of contextual data to collect. It is, however, infeasible to exhaustively collect every context that can influence energy usage using sensor deployments. There is a need, therefore, for systematic studies that use first principle approaches, such as directly interviewing with the user, to mine the key contextual causes that influence home energy consumption. This fundamental understanding can help more directed data collection of the most relevant context and can, consequently, be used to build better home energy management systems..

In this work, we conducted interviews across 22 diverse households in Baltimore City. The homes in our study include a range of occupant types, with variation across age, number of residents, and resident occupation. There is also significant variation in household income, ranging from less than $\$ 20,000$ per year to over $\$ 150,000$ per year. Finally, we interviewed residents who own their homes, as well as residents who rent their homes. This has given us a broad understanding of contextual factors deemed relevant across many types of homes.

Our participants discussed both novel and known influencing factors regarding home energy consumption. As a novel factor, we find that non-human occupants such as pets significantly influence home energy consumption. More wellknown, addressing issues in home construction, insulation, and appliance age is seen as a fiscally insurmountable barrier, suggesting that low-cost retrofit solutions would be beneficial. Household dynamics and hierarchy, as well as routine behavior and individual habits have a significant impact on energy management decisions or lack of action in many homes. Also, several of our participants talked about the impact of more recent environmental trends, such as the polar vortex and extreme summers, as a major cause of high electricity bills.

We also derived several findings regarding incentives underlying home energy management. We found, for example, that households in our study are primarily incentivized by reduction in their electricity bill rather than social responsibility. We conclude with a discussion of how these insights and findings speak to designing future home energy management systems.

\section{RELATED WORK}

Our work builds on previous research on collecting contextual data for home energy management and usability studies related to home energy consumption.

Collecting contextual data in the home: There is a large corpus of research in the sensor community that focuses on augmenting energy consumption or smart meter data with contextual data [18]. This data can help in building better predictive models of energy usage and better demand response systems. Collecting this data requires deploying sensors such as temperature, motion, light, and humidity [20], and inferring user activities such as cooking or work [7]. Unfortunately the approach taken in the sensor community is to first collect data 
from varied sensor modalities, and post-priori analyze the data to find ties between energy usage and the underlying context. We conjecture that building and deploying sensing systems for collecting energy annotations of context is futile without a proper understanding of the factors that affect home energy consumption. This is because there are several factors such as social structure, family hierarchy, and income bracket [12] in addition to known factors like household activity, occupancy that affect home energy consumption. Our approach to the problem is to use interviews to first understand the underlying causes of energy consumption in the home and then use these insights to build a sensor and user-driven home energy management system.

Usability studies related to home energy management: Our study is complementary to a large body of research in the HCI community on home energy management. These studies include understanding the main energy consumers in the home [6], eco-feedback systems [14] and evaluation of better visualization techniques [7] for home energy data. A subset of these systems strive to provide feedback [13] to the user on basic methods to monitor their energy consumption and adopt more environmentally conscious habits [5]. However, feedback often does not take into consideration other contextual aspects of the energy consumption, including social structure of the household residents, age of the home, location of the home in relation to others in the neighborhood, appliance age, occupant schedule and comfort within the home. Moreover, most usability studies have concentrated on a focussed group or population-e.g., low-income groups [8], and developing countries [25]. Our interview-based study strives to understand underlying factors governing home energy consumption, basic incentives that govern adoption of energy monitoring systems, and the types of energy measurement systems that users are comfortable with, for diverse demographics such as incomebracket, number of house occupants, and professional occupation.

\section{Understanding ENERGy USE PERCEPTIONS}

Our work is motivated by the following questions: What are the underlying factors that impact home energy consumption? and What are the incentives that govern home energy conservation? Our work differs from the literature described above in two ways. First, while most of the related work focuses on a niche population, for example, low income groups [9] or high and moderate income groups [5], we study the two questions using a participant group that is diverse in household income, occupant type, and type of housing. Unlike previous work, this diverse population helps us compare and contrast the factors that affect home energy consumption along several demographic dimensions. Second, our study provides a complete view of factors and incentives governing home energy consumption and energy conservation. This is unlike previous work that either focuses on incentives underlying home energy conservation alone [27], [12] or understanding what energy management techniques are applied by home owners [11], [28]

Study Methodology: We use a qualitative interview-based methodology for our study. We focused on Baltimore City,
Maryland as our hub for recruiting participants. Baltimore City is very diverse in the type of occupants and households, hence was an optimal location to recruit participants for our study. We recruited participants by sending emails to community groups, putting up flyers in different areas of Baltimore, advertisements on Craigslist and word of mouth approaches for recruiting participants for our study. We pre-screened our participants via a phone call and text messaging to get basic information on their demographics. The pre-screening helped us select a population group that is diverse along different demographic dimensions. Most of our participants were recruited via Craigslist. The participants were paid $\$ 10 /$ hour.

Participant Demographics and Interview Script: Our participant pool consists of twenty-two households. Table I details the income, age of the interviewee, gender of the interviewee, number of occupants, primary profession of the household, and type of housing, for the twenty-two households. We recorded 39 hours of interviews that were transcribed to 2258 lines of interview text. A key novelty of our dataset is the diversity along three dimensions for our participant groups: (1) Household income, (2) Occupant characteristics, and (3) Type of housing. The annual household income of our participants, for instance, varied from under $\$ 15,000 /$ year (low-income group [2]) to $\$ 150,000 /$ year (high income group [2]). Among our participants, household 3 and 13 relied on food stamps. Our subjects varied from 1-member households to 8-member households. We choose our interviewees from a wide pool of age groups, ranging from low 20s to high 50s, and professional occupation (graduate students, industrial professionals, unemployed). Another interesting demographic dimension of our dataset was the diversity in household structure and hierarchy. Households 3, 4, 8, 11, 13, and 20 had an explicit head of household like a family member or a landlord, while other households (1, 16, 18, and 19) had a flat household hierarchy. Half of our subjects lived in rental apartments while the other half owned their houses. This diversity helps us derive insights and correlate them with income brackets, occupant types, and housing types.

Data Analysis: Our interviews took place at various locations, depending on the participant's preference. Our interviews were semi-structured [15], i.e., while there was script for the interview, the participants were encouraged to discuss anecdotes, experiences, and present their own opinions regarding home energy management and conservation. We used a systematic methodology for analyzing the interview data. All our interviews were recorded and then transcribed. The transcribed interviews were manually analyzed and chunked into short stories. The stories illustrated important and interesting comments made by our participants. The stories were then analyzed and augmented with contextual tags. Each story was assigned as many contextual tags as possible. These tags correspond to high level factors like household occupancy, traditional techniques to saving energy, and incentives like saving money, or religious motivation for energy conservation.

\section{SAlient Insights}

Using the data analysis technique described in the previous section, we note novel insights as well as known factors 


\begin{tabular}{lclclc}
\hline Household \# & Income & Age (Gender) & \# occupants & Profession & Type of Housing \\
\hline 1 & $<15 \mathrm{~K}$ & 24 (Female) & 3 & Grad student & Apartment (rental) \\
\hline 2 & $150 \mathrm{~K}$ & 32 (Female) & 2 & Lawyer & Rowhome (owned) \\
\hline 3 & $15-30 \mathrm{~K}$ & 43 (Male) & 3 & Food stamps & Rowhome (rental) \\
\hline 4 & $15 \mathrm{~K}$ & 46 (Female) & 2 & Grad student & Rowhome (own) \\
\hline 5 & $76-100 \mathrm{~K}$ & 49 (Male) & 1 & Engineer & Apartment (rental) \\
\hline 6 & $76-100 \mathrm{~K}$ & 33 (Female) & 1 & Marketing & Rowhome (owned) \\
\hline 7 & $15-30 \mathrm{~K}$ & 23 (Female) & 5 & Unemployed & Single Family (owned) \\
\hline 8 & $15-30 \mathrm{~K}$ & 21 (Female) & 8 & Landscaping & Single Family (owned) \\
\hline 9 & $15-30 \mathrm{~K}$ & 18 (Male) & 7 & Odd jobs & Single Family (owned) \\
\hline 10 & $51-75 \mathrm{~K}$ & 24 ( Male) & 2 & Grad student & Apartment (rent) \\
\hline 11 & $150 \mathrm{~K}$ & 45 (Male) & 4 & DoD & Rowhome (owned) \\
\hline 12 & $76-100 \mathrm{~K}$ & 29 (Female) & 2 & Speech pathologist & Rowhome (owned) \\
\hline 13 & $<15 \mathrm{~K}$ & 54 (Female) & 1 & Food stamps & Apartment (rental) \\
\hline 14 & $150 \mathrm{~K}$ & 53 (Male) & 1 & Software developer & Single Family (owned) \\
\hline 15 & $31-50 \mathrm{~K}$ & 54 (Female) & 3 & Food stamps & Single Family (owned) \\
\hline 16 & $<15 \mathrm{~K}$ & 23 (Female) & 4 & Grad student & Apartment (rental) \\
\hline 17 & $76-100 \mathrm{~K}$ & 50 (Male) & 5 & Office manager & Rowhome (rental) \\
\hline 18 & $15-30 \mathrm{~K}$ & 35 (Male) & 4 & Graduate assistant & Rowhome (rental) \\
\hline 19 & $15-30 \mathrm{~K}$ & 29 (Male) & 3 & Grad student & Apartment (rental) \\
\hline 20 & $31-50 \mathrm{~K}$ & 50 (Male) & 1 & Truck driver & Apartment (rental) \\
\hline 21 & $31-50 \mathrm{~K}$ & 38 (Male) & 3 & Restaurant server & Rowhome (owned) \\
\hline 22 & $>100 \mathrm{~K}$ & 33 (Male) & 2 & Network admin & Rowhome (owned)
\end{tabular}

TABLE I. THE TABLE ILLUSTRATES THE WIDE RANGE OF DEMOGRAPHICS FOR OUR 22 PARTICIPANTS. THE DIFFERENT DEMOGRAPHIC DIMENSIONS INCLUDE INCOME GROUP, INTERVIEWEE AGE, NUMBER OF HOUSEHOLD OCCUPANTS, TYPE OF HOUSING, AND PROFESSION.

affecting the relationship between home energy technology and residential consumers.

Insight 1: Non-human occupants, including pets, significantly impact home energy consumption.

While it is well known that occupancy and user schedule is a primary determinant of home energy consumption [21], the focus of past energy management systems has been on human occupancy. For instance, state-of-the-art technology like the Nest Learning Thermostat, [10] or research prototypes like PreHeat [24], control a home HVAC system solely based on human occupancy.

Our interviews revealed that collecting context on human occupancy is not sufficient, and pets (dogs specifically) are a critical factor in determining home energy consumption. Nine households in our study had pets, and many of the pets stay home when the homeowner is at work multiple days of the week. Our participants commented that various adjustments to the heating and cooling system were made for the comfort of the pet. For instance, participant 2 (high income, lives in a row home) mentioned:

The heat has to be adjusted for the dog. We can't let

it be too cold in the house when we are gone.

Similarly, participant 9 (low income group, lives in a single family home) commented:

We will often leave the lights on in the house for the

dog if we are all out of the house.

While there was concern regarding making sure dogs were comfortable, cats did not receive the same treatment. Surprisingly, cats were dismissed as something one would change their energy consumption patterns over. Of our 6 households that had cats, all stated that they would never think of adjusting their power for the comfort of the cats. For instance, participant 11 (high income, lives in a row home), commented:
We have a cat but she doesn't influence energy at all; we don't change anything for her.

In addition to common pets such as dogs and cats, other nonhuman occupants such as fish residing in aquariums, plants and terrariums, were also discussed as factors impacting energy use. Participant 22 (high income, lives in row home) stated:

We have to keep the house warmer because we have lots of plants, including a lemon tree and a lime tree.

Participant 15 (low income, lives in a single family home) mentioned:

We have a large aquarium that has to be kept at a certain temperature as well as it has it's own lighting.

Correlation with Demographics: The impact of pets was mentioned by participants across income groups, house types, and occupation. Quantitatively, 33\% of the participants who mentioned pets belonged to the low income group, 67\% belonged to moderate and high income households, $78 \%$ lived in user-owned homes, while $22 \%$ lived in rentals. The above data shows that non-human occupants affect home energy consumption across a wide range of demographics, and must be generally considered in the design of energy management systems.

Implication to Energy Management Systems: The above insight illustrates the need for energy management systems that can adapt HVAC settings based not only on home occupancy, but specifically based on the type of occupant (i.e., human versus pet). Moreover, it is important to be able to distinguish different types of non-human occupants (i.e., cats versus dogs). Currently, a system like Nest allows users to manually choose the appropriate away temperature for a home. A user with a dog would set this temperature to be appropriate for the pet, however this would remain the away temperature even in case 
the pet were also not home as the Nest sensors do not detect pet occupancy. Augmenting this kind of system to adjust to pets could use an automatic technique to detect human and nonhuman occupants as well as distinguish pets from one another by using pressure sensors built into door mats [16].

Insight 2: Addressing issues of home construction and appliance age is seen as an important barrier, suggesting that low-cost retrofit solutions would be beneficial.

Poor home insulation and old, energy-inefficient appliances can become primary causes of high energy usage in buildings. To address this problem, households resort to energy audits where an expert diagnoses problems with home construction and appliances, and recommends solutions such as purchase of energy-star appliances. The energy audits and their proposed remedies, however, can be prohibitively expensive. In previous work, home construction issues have been attributed primarily to low income brackets [9], [6]. Our study, however, shows that participants in both low-income and high-income households have concerns about excessive energy consumption due to poor home insulation, home construction, and old appliances. More than $64 \%$ of all the homes in the low income group and $71 \%$ of the households in the high income bracket mentioned poor insulation and home construction material as a major cause of excessive energy usage. Similarly $36 \%$ of low-income households and $43 \%$ of the high-income households complained that old appliances were a major power sink. Moreover, perhaps counterintuitively, both high income and low income groups resorted to undesirable makeshift and retrofit solutions to circumvent the problem. For instance, participant 5 (highincome group, lives in an apartment), and participant 17 (highincome group, lives in a row home) stated:

My windows and doors are the worst. I can hear the wind coming through the windows; I'm thinking of putting that wrap around them but it's so ugly.

Our washer is energy efficient but our dryer is super old. Sometimes I think air drying our stuff would be faster!

In our study, the higher income groups also mentioned cost barriers to replacing appliances or installing better insulation, the underlying reason was attributed to instability of the economy and their unwillingness to sink money into property that may not provide a sufficient return on the investment. For instance, participant 14 ( high-income, lives in a single family home) mentioned:

My house was built in 1958 and I know the insulation is lacking. I installed passive solar, but now with the economy like it is, I am not sure it's wise to spend that much money putting in new insulation.

Correlation with Demographics: Unlike previous work [9] that attributes home insulation problems solely to low-income populations, we found that both low income and high income households had concerns about home insulation and construction. For instance, $64 \%$ of the participant households in the very low income group $(<\$ 30 \mathrm{~K} / \mathrm{yr}$. $)$ and $71 \%$ of the households in very high income group $(>\$ 70 \mathrm{~K} / \mathrm{yr}$.) thought that home construction was a major energy consumer. Only $50 \%$ of the moderate income group (between $\$ 50 \mathrm{~K}-\$ 70 \mathrm{~K} / \mathrm{yr}$.), however, mentioned home construction problems. Similar to previous work [4], [9], [6], we attribute the home construction problem in low-income neighborhoods to minimal effort paid on renovations and energy audits. The insulation problem in high income bracket participants could be due to extreme weather conditions and the lack of enthusiasm of participants to invest in their homes. The moderate income groups mostly live in rentals, hence, the insulation issues are resolved by a central entity like a landlord. We saw similar correlations for energy consumption due to old appliances (36\% of the low income participants, $25 \%$ of moderate income individuals, and $43 \%$ of the high income participants complained about old appliances).

Implication to Home Energy Management: Most of our participants felt that home construction and aging appliances were difficult and expensive problems to address. Moreover, detecting problems in home construction and old appliances was a manual process. The key to an economical solution to addressing home construction and appliance age issues is to automatically determine where retrofit solutions would lead to the most substantial energy savings, for example by automatically identifying major home insulation and leakage hotspots or malfunctioning appliances. To address the above problem, sensor-based virtual auditing systems that use low-cost off-theshelf inexpensive energy meters to measure appliance energy draw, and door and window moisture sensors to determine major insulation hotspots, can be used. The homeowner can then apply the retrofit solutions to address the most critical home construction and appliance malfunction problems. For instance, the largest air leakage due to improper insulations can be resolved through thicker curtains to create a double glazing effect, and foam, cotton wool or insulating material can be used to fill in leaks.

Insight 3: Household dynamics and hierarchy have a significant impact on energy management decisions.

It has been demonstrated in previous work that the design of systems inside the home is affected by gender role and home structure [26]. In our study, we found that home energy consumption is also affected by household dynamics and household hierarchy. Some households in our study consisted of families with a clear "leader", such as the grandmother, mother, or landlord/owner of the house, who set expectations and limitations on energy use. These "leaders" also enforce access control and energy management policies. For example, participant 8 (low-income), who lives in single home house pointed out:

\section{My grandmother unplugs everything when we aren't using them: the TV, lights, etc}

Similarly, in families with toddlers and infants, the parents share the leadership role and determine which activities must be frequently performed, which in turn affects home energy usage. For instance, participant 4 (low-income, lives in a row home), mentioned:

My daughter takes baths often, so that uses hot water, the hot water heater.

We keep the house warmer than previously because we have a new baby. We also do the baby's laundry 
separately because we have to use special detergent for her stuff.

In rental apartments, we saw similar effects of household hierarchy where the landlord or the home owner made energy management decisions for the house. Participant 13 (lowincome, lives in a apartment) and participant 5 (high-income, lives in an apartment), respectively commented:

My heat was off for almost two days. I called the landlord to fix it but he wasn't in any hurry to help me. Turns out that it was just a switch on the heating unit. I don't know why it was such a big deal

Households without a clear "leader" had a flat structure with roommates or couples who were keen on compromising. Making optimal energy management decisions in a flat household, however, is more challenging since the system must be cognizant of conflicting occupant comfort and appliance usage preferences. Participant 18 (low-income, lives in a row home), commented on the conflicting preferences for setting the heating with his roommate:

My roommates and I try to work out the heating, but I am on the third floor and it is extremely hot up there so I often have the fan on or the window cracked even in the winter.

Our participants also commented on how the conflicting comfort and appliance usage preferences amongst occupants can lead to substantial energy draw. For instance, participant 3 (low-income, lives in a row home apartment) who lives with his partner mentioned:

My significant other has the fan on even in the winter. She is hot all the time. I've taken to cracking the windows to keep the circulation up and I don't like having the fan blowing on me when I sleep.

Correlation with Demographics: Of the 22 participants in our study 12 households had a flat family structure and 6 households had a hierarchical ("leader"-based) structure, and we could not infer the family structure of the remaining 4 participants. We also saw a correlation between a hierarchical household and income bracket. $67 \%$ of the households that were hierarchical belonged to the low-income bracket, while $58 \%$ of all the households that had a flat family structure belonged to moderate and high-income bracket. $80 \%$ of the households that had a flat household and were low-income were graduate students, implying that most of the households that had a permanent job and had a flat family structure belonged to moderate and high income bracket. Similarly, families with a hierarchical structure had an average of 4.8 +/- 2.3 (standard deviation) occupants per household, and the families with a flat family structure had an average of 2.9 +/- 0.99 (standard deviation) occupants. These results demonstrate a correlation between family structure and number of occupants and income bracket.

Implication to Home Energy Management: The above insight points to the need for energy management systems that account for family structure and hierarchy. In a family with a flat hierarchy, it is important that energy optimizations be cognizant of different comfort preferences, conflicting appliance usage, and conflicting needs of the residents. Clearly building such energy management systems is difficult. More recent methods to address the problem involves taking multiple occupants' opinions into account, and performing optimization to maximize the comfort for a maximal number of occupants [6], [19], [17], [3]. In a hierarchical family structure, however, the problem is easier since the system can be tuned to the preferences of the "leader" in the house. Similar to previous work on security systems in the home [22], the family structure can also inform the type of home energy management system that should be deployed inside the house. For instance, if the "leader" in the house is not tech-savvy, it is counter-productive to build control systems that require the use of technology like smartphone-based controllers.

Insight 4: Routine behavior and individual habits are perceived as significant determinants of energy consumption, and users desire feedback on the energy impact of activities.

Ronis et al. [23] point out that daily habits can adversely affect the environment. In our study, we found that participants had quotidian habits that could both adversely and favorably affect their home energy consumption. While the participant were cognizant of these habits, they were often unable to quantify their importance or effect on home energy consumption. For instance participant 18 (low-income, lives in a row home apartment) pointed out:

I go outside to smoke 6-7 times in an evening. I am opening the back door and then the garage door, so that uses electricity. We also open the back door for the dogs all the time. In the evening the motion light goes on each time we go out there or send the dogs out. (Adverse effect on environment)

Five of our participants similarly pointed out the use of traditional methods for drying clothes instead of a dryer.

We have a clothesline outside for when the weather is nice. We also have a line in the basement for the bad weather. I don't remember the last time we used the dryer. (Favorable effect on environment)

and participant 15 (low-income, lives in a single family home) commented:

I don't have a dishwasher but I always wonder if having a dishwasher would save more energy

15 participants mentioned using traditional energy-saving methods like air drying clothes, washing dishes, and using curtains for insulation, but they mentioned their frustration and inability to quantify whether these individual habits had a favorable effect on home energy consumption. Though heating, cooling, and lighting systems are traditionally cited as the largest consumers of energy [1], few of our participants were concerned about the energy consumption of these appliances. In contrast, many participants were curious about the energy consumption of smaller appliances that they interact with regularly, suggesting lack of clear understanding regarding major consumers of home energy. Participants 15 mentioned the need to understand energy consumption of smaller appliances.

We have a lot of those wall plug ins that make the house smell better. They are everywhere. We have a lot of kitchen appliances, including a juicer. I would 
like to know how these influence our bill. Do they make a big difference?

In our study routine behavior and individual habits was pervasively mentioned by participants across income groups, occupation, and house types.

Implication to Home Energy Management: The above insight points to the need for feedback-based energy management systems. While daily habits can occur without conscious thinking [13], it is important that the pros and cons of certain habits be quantitatively presented before the user. Our insight shows that this should happen not only for habits that have a negative impact on home energy consumption, but even for habits that have a positive impact on home energy usage. For instance, a eco-feedback system [14], that provides feedback on the benefits of hand washing the dishes over using a dish washer can help the user understand the benefit of this habit. Additionally, user-centric systems like smart phone applications can be used to show the impact of smaller appliances and, hence, help the user understand that the major determinants of home energy consumption are larger appliances like HVAC.

\section{CONCLUSIONS}

In this paper, we study the underlying factors influencing home energy usage. For our study, we conducted semistructured interviews with 22 participants in Baltimore City, Maryland. We draw several insights into the underlying complexities of energy use in homes. For example, we show that non-human occupants (pets and plants) and family dynamics and hierarchy have a major impact on home energy consumption. Additionally, addressing issues of home construction and appliance age is seen as an important barrier by households across income groups, suggesting that lowcost retrofit solutions would be beneficial. Moreover, our participants mentioned the adverse effect of the polar vortex and extreme summers on their electricity bill.

Acknowledgements: This material is based upon work supported by the National Science Foundation under awards CNS1305099 and IIS-1406626, CNS-1308723, CNS-1314024, and the Microsoft SEIF Awards. Any opinions, findings, and conclusions or recommendations expressed in this material are those of the authors and do not necessarily reflect the views of the NSF or Microsoft.

\section{REFERENCES}

[1] Heating and cooling no longer majority of U.S. home energy use (http://www.eia.gov/todayinenergy/detail.cfm?id=10271) 2014.

[2] Office of Assistant Secretary, World Robot Control Software. http: //aspe.hhs.gov/poverty/14poverty.cfm, 2014.

[3] Agarwal, Y., Balaji, B., Gupta, R., Lyles, J., Wei, M., and Weng, T. Occupancy-driven energy management for smart building automation In BuildSys, ACM (2010), 1-6.

[4] Blumstein, C., Krieg, B., Schipper, L., and York, C. Overcoming social and institutional barriers to energy conservation. Energy 5, 4 (1980), 355-371.

[5] Bourgeois, J., van der Linden, J., Price, B., and Kortuem, G. Technology probes: experiences with home energy feedback.
[6] Chetty, M., Tran, D., and Grinter, R. E. Getting to green: understanding resource consumption in the home. In Ubicomp, ACM (2008), 242-251.

[7] Costanza, E., Ramchurn, S. D., and Jennings, N. R. Understanding domestic energy consumption through interactive visualisation: a field study. In Ubicomp, ACM (2012), 216-225.

[8] Dillahunt, T., and Mankoff, J. Understanding factors of successful engagement around energy consumption between and among households.

[9] Dillahunt, T., Mankoff, J., Paulos, E., and Fussell, S. It's not all about green: Energy use in low-income communities. In Ubicomp, ACM (2009), 255-264.

[10] Fadell, A. M., Rogers, M. L., Sloo, D., Matas, M. J., Bould, F., Honjo, S., Huppi, B., and Filson, J. B. Thermostat user interface, Oct. 22012. US Patent 8,280,536.

[11] Fischer, C. Feedback on household electricity consumption: a tool for saving energy? Energy efficiency 1, 1 (2008), 79-104.

[12] Fréjus, M., and Guibourdenche, J. Analysing domestic activity to reduce household energy consumption. Work: A Journal of Prevention, Assessment and Rehabilitation 41 (2012), 539-548.

[13] Froehlich, J. Promoting energy efficient behaviors in the home through feedback: The role of human-computer interaction. In Proc. HCIC Workshop, vol. 9 (2009), 1-11.

[14] Froehlich, J., Findlater, L., and Landay, J. The design of eco-feedback technology. In CHI, ACM (2010), 1999-2008.

[15] Fylan, F. Semi structured interviewing. A handbook of research methods for clinical and health psychology (2005), 65-78.

[16] Hong, X., Nugent, C., Mulvenna, M., McClean, S., Scotney, B., and Devlin, S. Evidential fusion of sensor data for activity recognition in smart homes. Pervasive and Mobile Computing 5, 3 (2009), 236-252.

[17] Klein, L., Kwak, J.-y., Kavulya, G., Jazizadeh, F., Becerik-Gerber, B., Varakantham, P., and Tambe, M. Coordinating occupant behavior for building energy and comfort management using multi-agent systems. Automation in Construction 22 (2012), 525-536.

[18] Kulkarni, A. S., Welch, K. C., and Harnett, C. K. Modeling human behavior for energy-usage prediction. In HCI International 2011. Springer, 2011, 298-302.

[19] Lu, J., Sookoor, T., Srinivasan, V., Gao, G., Holben, B., Stankovic, J., Field, E., and Whitehouse, K. The smart thermostat: using occupancy sensors to save energy in homes. In Sensys, ACM (2010), 211-224.

[20] Pierce, J., and Paulos, E. Beyond energy monitors: interaction, energy, and emerging energy systems. In CHI, ACM (2012), 665-674.

[21] Pierce, J., Schiano, D. J., and U of Arkansas, E. Home, habits, and energy: Examining domestic interactions and energy consumption. In CHI, CHI '10, ACM (New York, NY, USA, 2010), 1985-1994.

[22] Rode, J. A. The roles that make the domestic work. In CSCW, CSCW '10, ACM (New York, NY, USA, 2010), 381-390.

[23] Ronis, D. L., Yates, J. F., and Kirscht, J. P. Attitudes, decisions, and habits as determinants of repeated behavior. Attitude structure and function (1989), 213-239.

[24] Scott, J., Bernheim Brush, A., Krumm, J., Meyers, B., Hazas, M., Hodges, S., and Villar, N. Preheat: controlling home heating using occupancy prediction. In Ubicomp, ACM (2011), 281-290.

[25] Shrinivasan, Y. B., Jain, M., Seetharam, D. P., Choudhary, A., Huang, E. M., Dillahunt, T., and Mankoff, J. Deep conservation in urban india and its implications for the design of conservation technologies. In CHI, CHI '13, ACM (New York, NY, USA, 2013), 1969-1978.

[26] Voydanoff, P. Work role characteristics, family structure demands, and work/family conflict. Journal of Marriage and the Family (1988), 749761.

[27] Winett, R. A., Kagel, J. H., Battalio, R. C., and Winkler, R. C. Effects of monetary rebates, feedback, and information on residential electricity conservation. Journal of Applied Psychology 63, 1 (1978), 73.

[28] Woodruff, A., Hasbrouck, J., and Augustin, S. A bright green perspective on sustainable choices. In CHI, ACM (2008), 313-322. 